\section{Museo Farol de Santa Marta Cascais, Portugal}

En un sitio donde se superponen intervenciones y diferentes materialidades, se rehabilita un farol para convertirlo en espacio público y museo. La apertura del lugar al contexto, su situación en la península y los rincones que se proyectan dan cabida al paseo, la detención y la contemplación.
In a site where interventions and differing materialities are superimposed, a lighthouse is rehabilitated and converted into a museum and public space. The opening of the place in its context, its situation on the peninsula and the corners that are designed give place to the outing, pause and contemplation.

Francisco Aires Mateus Profesor, Universidade Autónoma de Lisboa y Universitá della Svizzera Italiana

Manuel Aires Mateus Profesor, Universidade Autónoma de Lisboa, Universitá della Svizzera Italiana y Universidade Lusíada

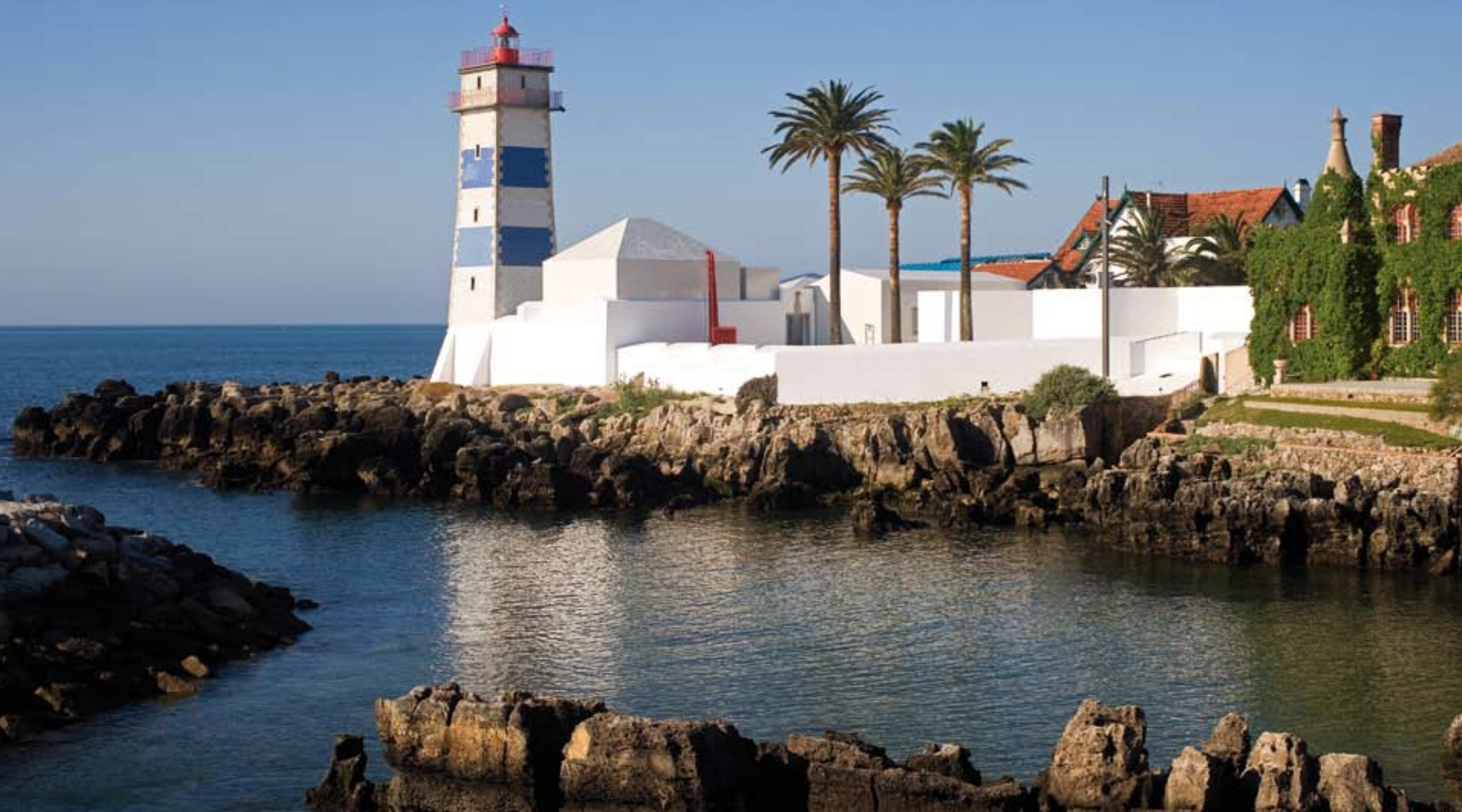




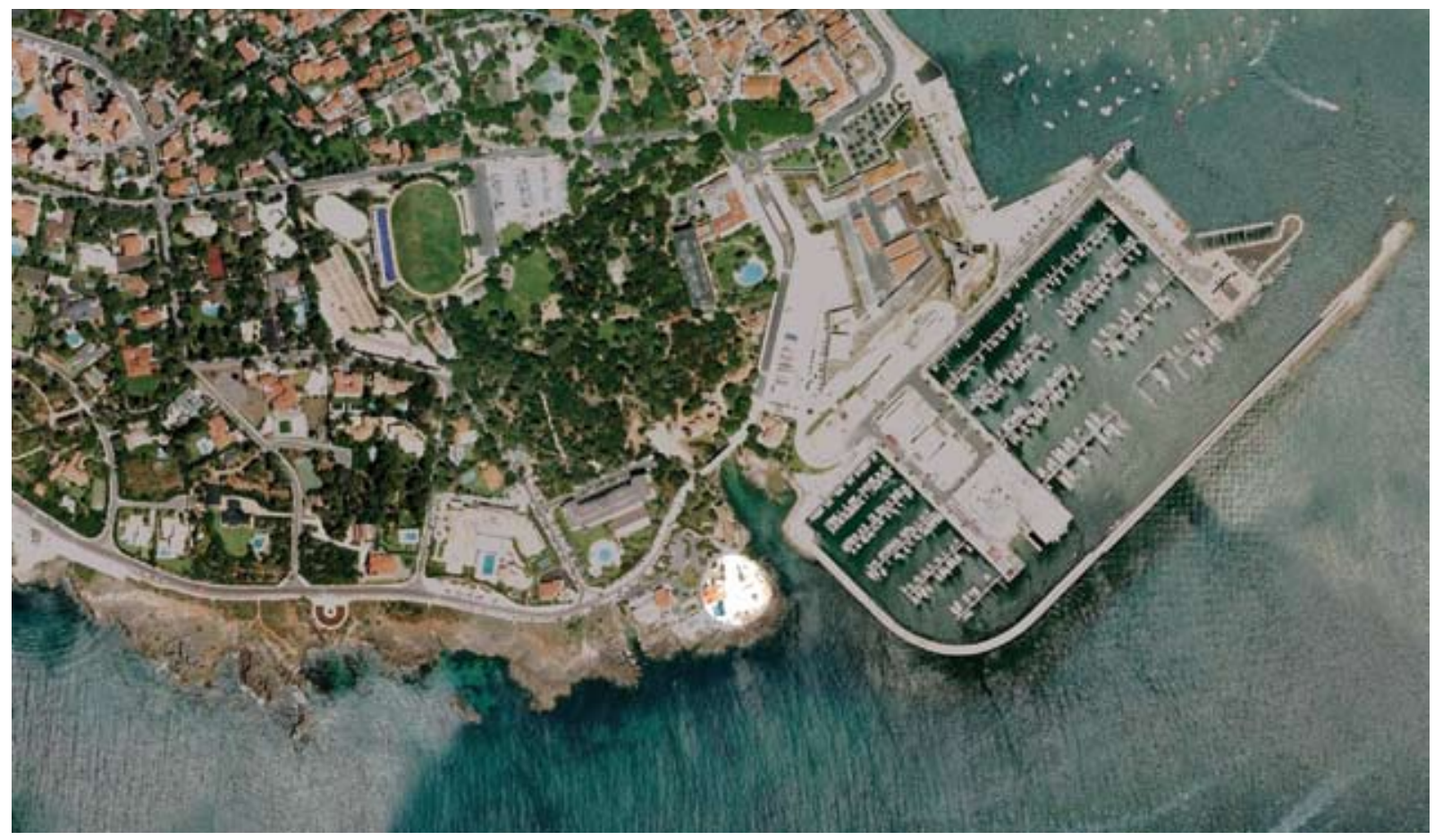

Emplazamiento Museo Farol de Santa Marta, Cascais, Portugal. Fuente: Servicio de imágenes del planeta Google EarthT

Justo entre la tierra y el mar, sobre un trozo de terreno en permanente cambio a través del tiempo, la intervención humana ha alcanzado sus más variadas soluciones. Desde el s. xvII una serie de planes fueron superponiéndose en este lugar; los recursos tecnológicos y materiales empleados en cada época y su convivencia con el grandioso patrimonio, concurren en una serie de transformaciones y extensiones del territorio. Los aspectos arquitectónicos locales, unidos a una lectura inequívoca del lugar fueron, como nunca antes, aspectos primordiales en los principios organizacionales del proyecto. La adulteración y deterioro de algunas de sus partes son la consecuencia de un proceso de selección natural que el proyecto busca revertir para su propio beneficio. Se escogieron los elementos de mayor permanencia y valor poético; la propuesta reconstruye con ellos y desde ellos un orden fundacional, encapsulando la memoria del tiempo pasado, a través de su nuevo uso como museo-farol.

En este proyecto las fuerzas existentes abruptamente convergen: su historia, su memoria y su capacidad de transformación. Como consecuencia, el proyecto es construido desde un legado significante y está hecho de formas, espacios y sistemas constructivos basados en sus propios procesos históricos. Esto se vuelve visible en la morfología y estado actual del edificio para expresar una visión clara del futuro. El objetivo es reemplazar el orden original a través del entendimiento del tiempo, acogiendo un nuevo uso, registro preciso de sucesivas contemporaneidades. ARa

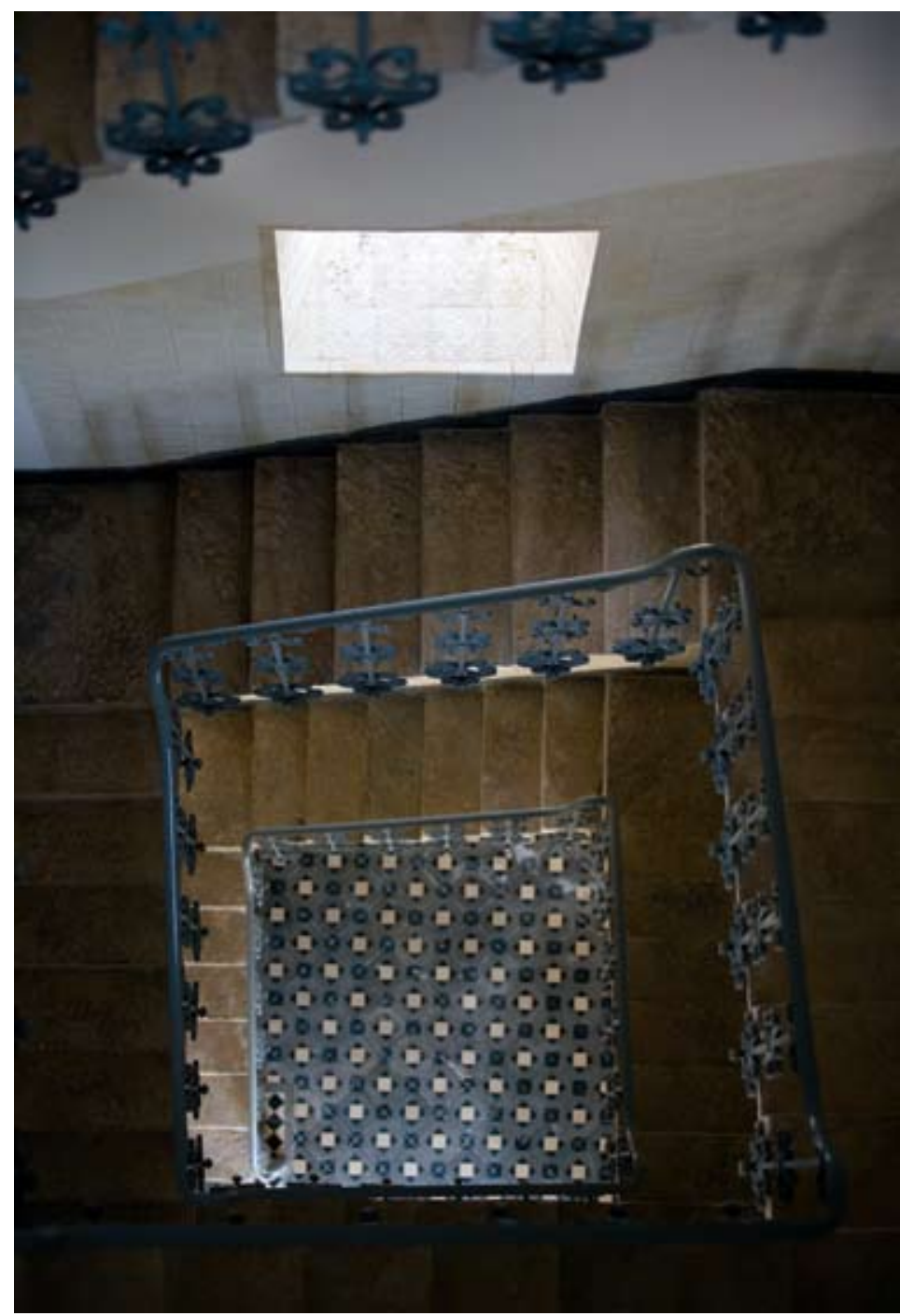

Rehabilitación escalera Farol de Santa Marta. 


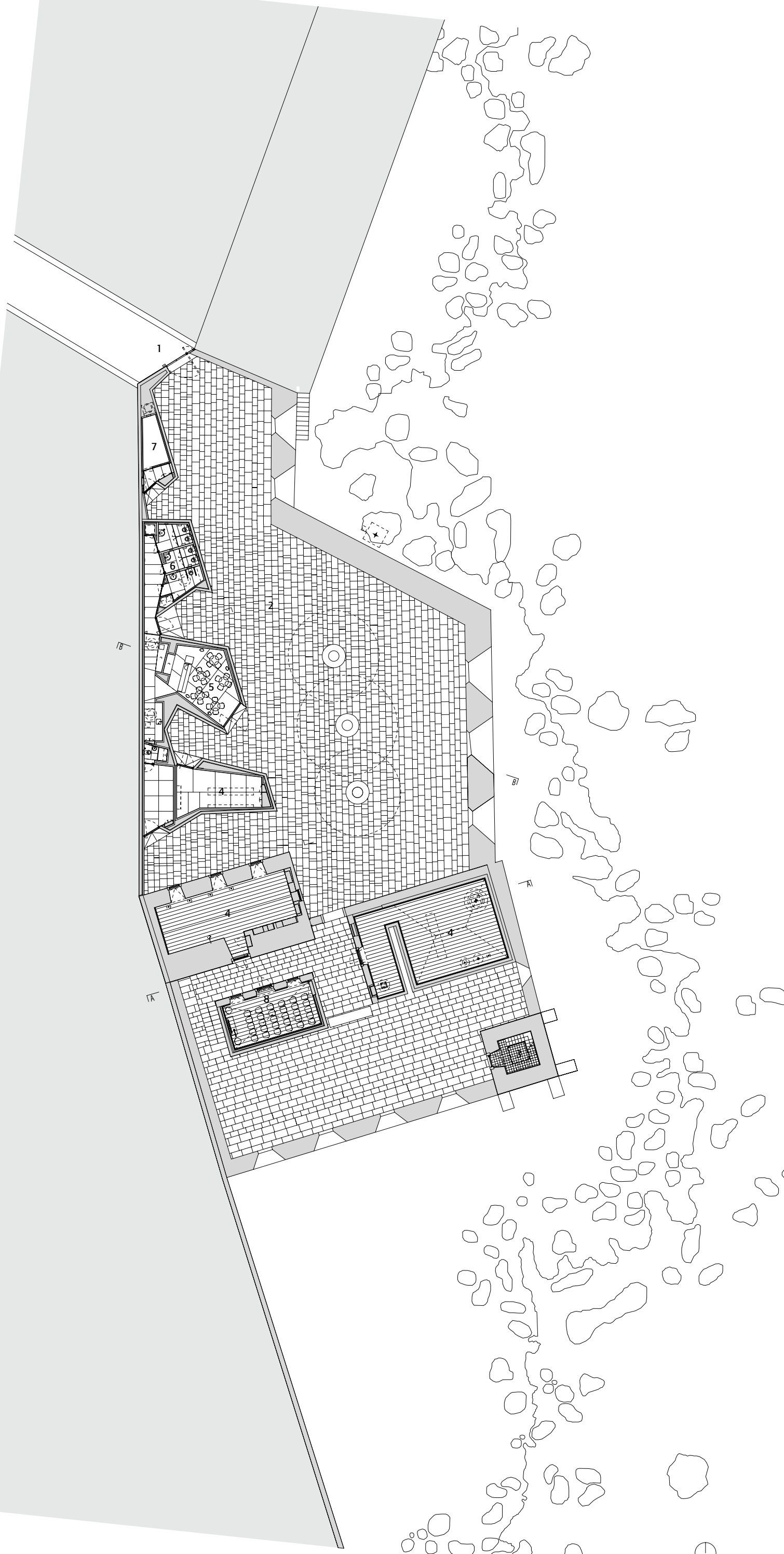




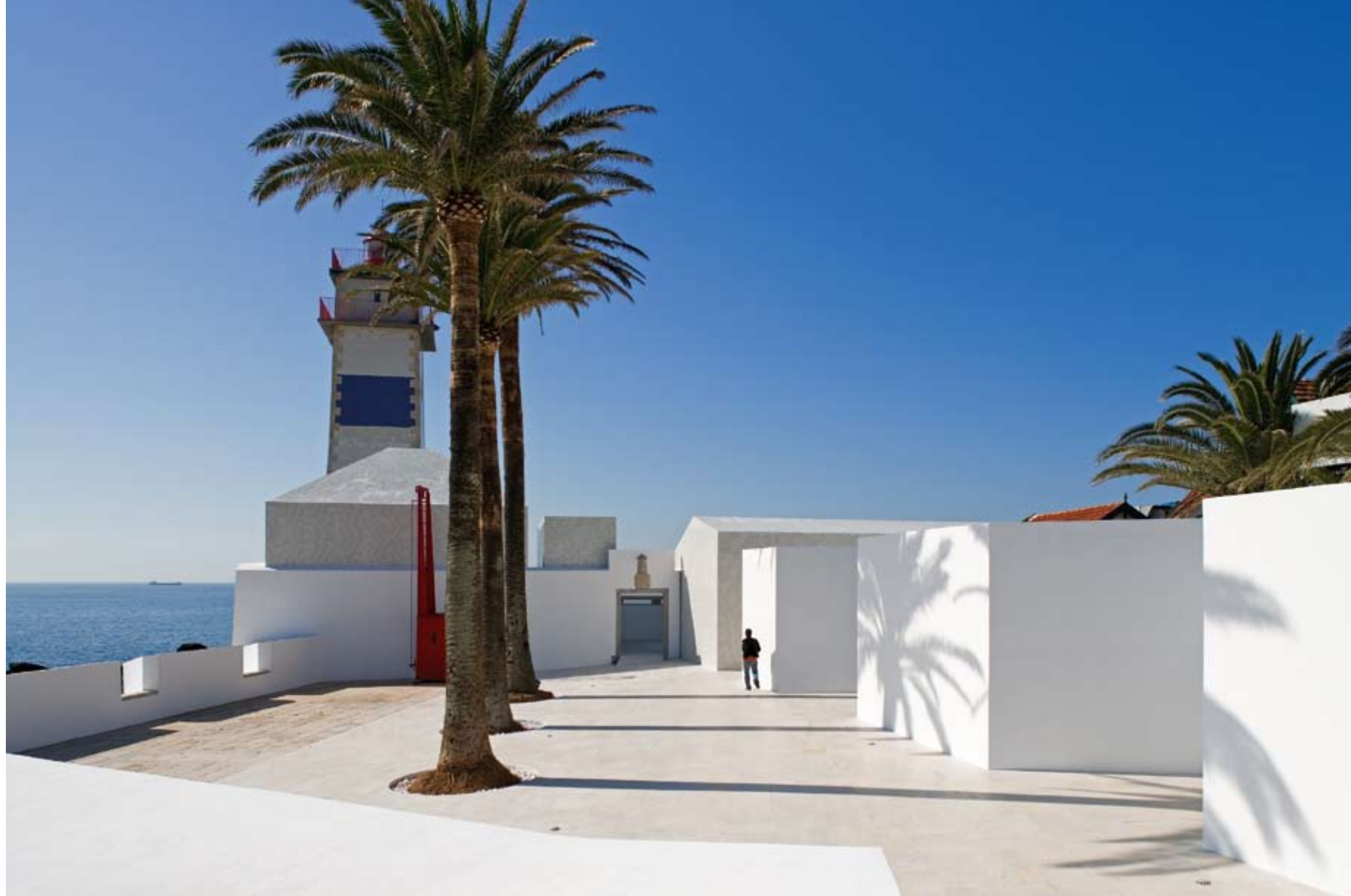




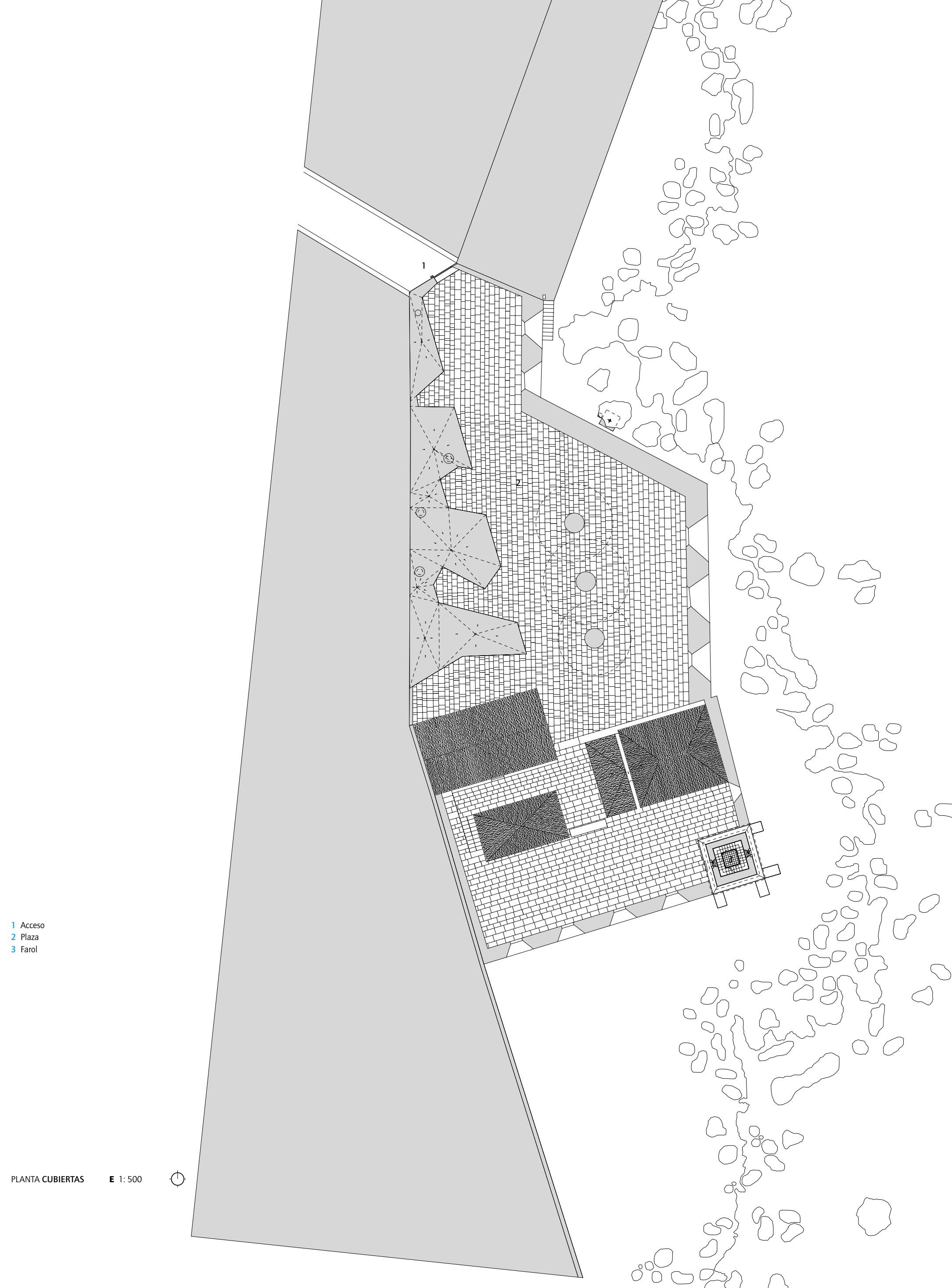




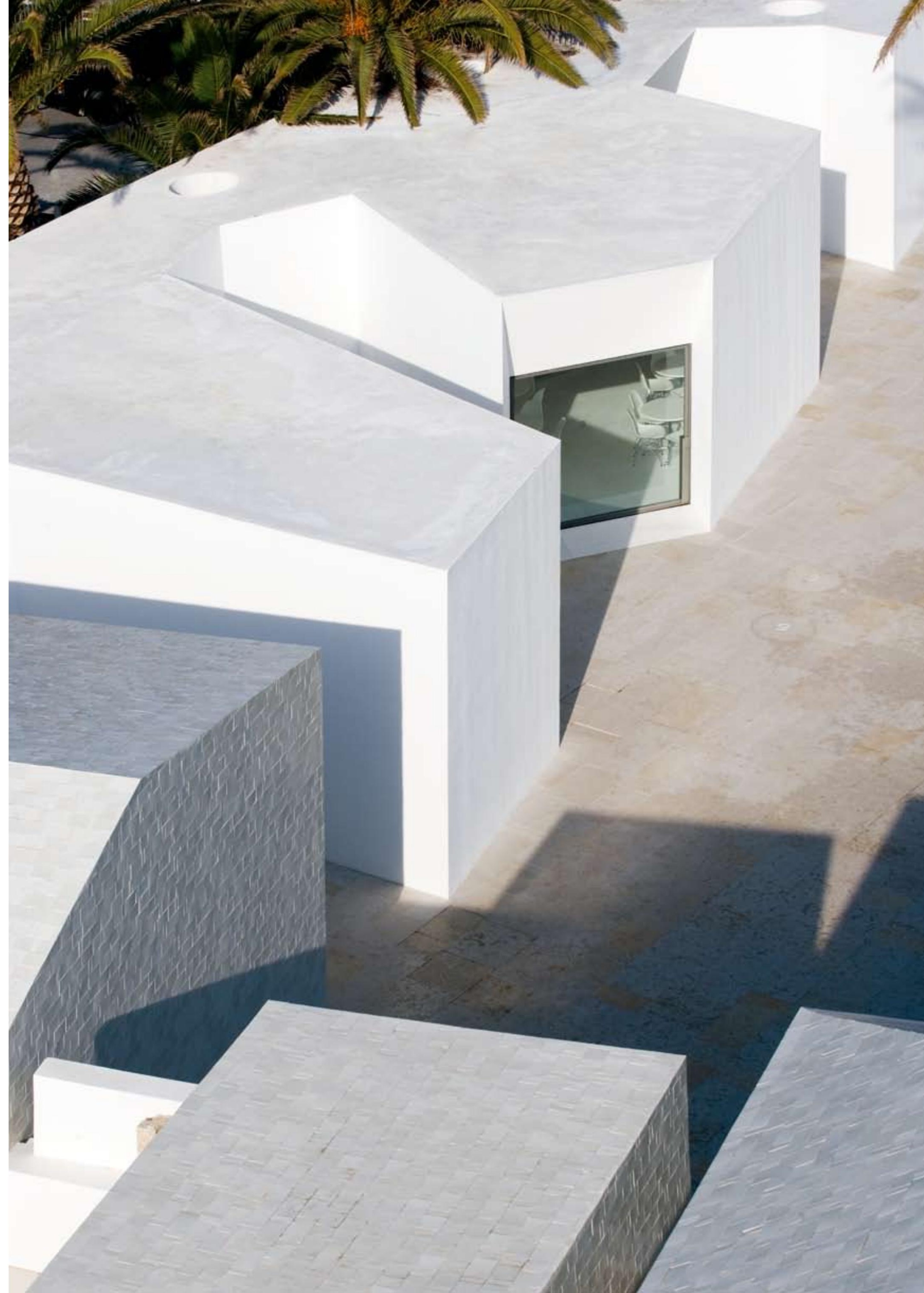



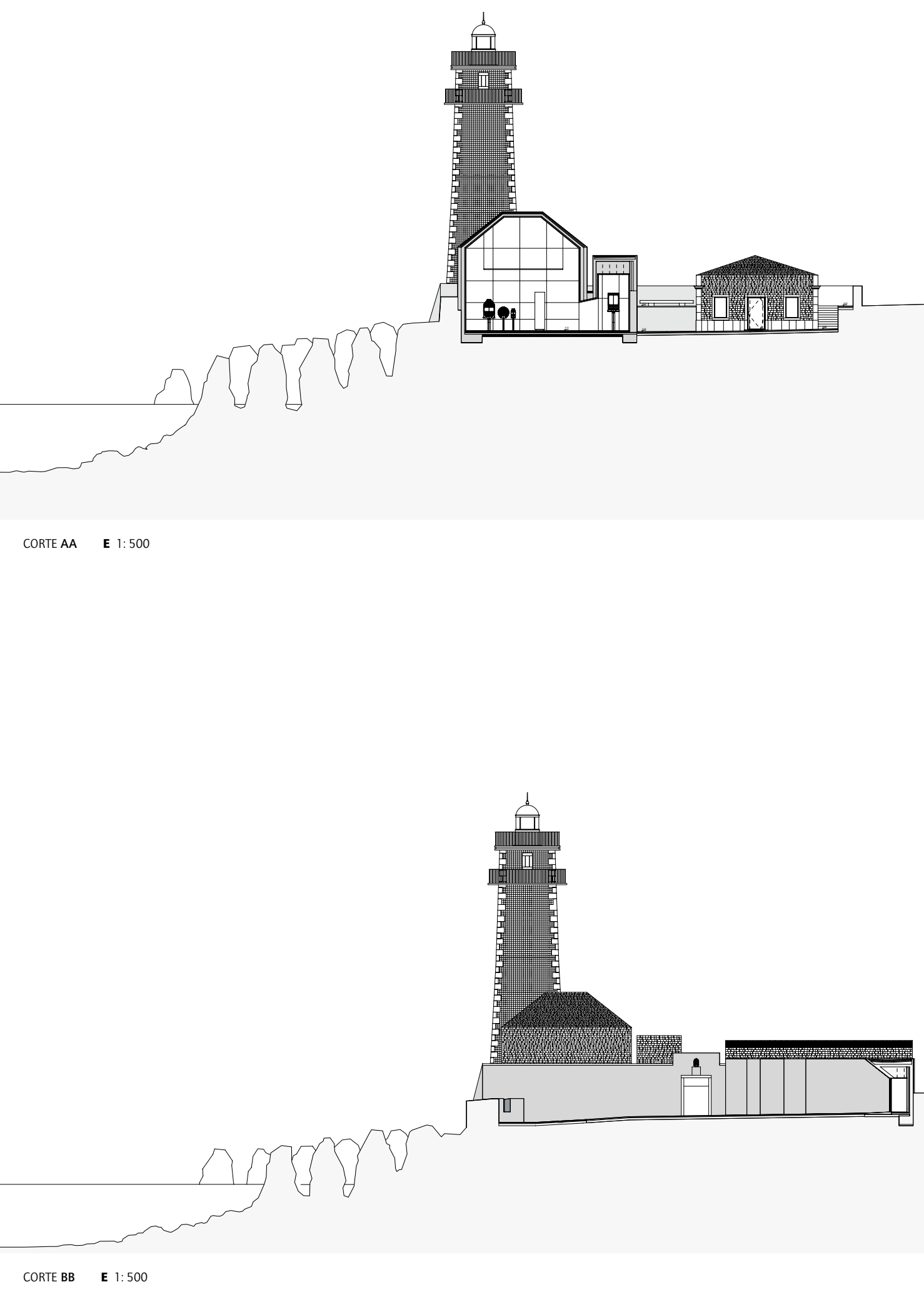

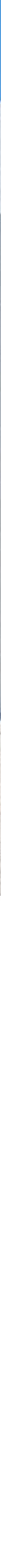

MUSEO FAROL DE SANTA MARTA

Arquitectos Francisco Aires Mateus, Manuel Aires Mateus Colaboradores Sofía Chinita Janeiro, Filipe Boím

Ubicación Cascais, Portugal

Cliente Cámara Municipal de Cascais

Cálculo estructural Joel Sequeira

Construcción Udra Constructora, Lda.

Instalaciones eléctricas Joule

Materialidad estructura de muros de piedra existente, muros y losas de hormigón armado, revestimientos de muros en azulejos, pisos interiores en madera de pino americano y mármol, pisos exteriores existentes en piedra. Presupuesto sin datos

Superficie terreno $1.750 \mathrm{~m}^{2}$

Superficie construida $435 \mathrm{~m}^{2}$

Año proyecto 2003

Año construcción 2003-2007 